on examination nothing to account for it was found. Her appetite was bad and she complained of a foul taste in the mouth; there was still considerable dyspncea. The left pleural cavity was accordingly aspirated, but little improvement resulted, and the patient died on May 18th. On the day before her death the stools were noticed to be very black in colour, suggesting hæmorrhage.

Neoropsy.--At the post-mortem examination, made by Dr. William Hunter, the glands in the mesentery and along the aorta were found to be much enlarged and the lymphatics of the pelris were dilated so as to resemble the condition found in filariasis. The left ovarian and renal veins and the right common iliac vein were thrombosed and impervious, the liver was fatty, the kidneys were normal, and the spleen was shrunken and atrophied; the intestines contained altered blood but were themselves healthy. On the lesser curvature of the stomach was an ulcer $1 \frac{1}{2}$ in. in diameter, cleanly punched out and circular in shape; the viscus was partially filled with altered blood. The vagina and body of the uterus were normal; the cervical canal was inflamed and contained a sanguineous discharge. No trace of any operation on these parts could be found. The right pleural cavity contained over two pints of blood-stained serum; both the visceral and parietal layers of pleura were studded with small nodules of vascular new growth. The heart was healthy; the pericardium contained several ounces of bluish serum. The lower lobe of the left lung was in a condition of hypostatic congestion and showed some old cicatrices. In the right lung the lower lobe was collapsed and puckered into a mass of new growth which occupied the lower posterior margin. The growth was pigmented and caseous in parts. The glands on the left side of the neck were much enlarged. The internal jugular and subclavian veins were thrombosed at their junction to form the left innominate vein, and this ressel was also blocked at its junction with the vena cava and contained a quantity of milky fluid, apparently accumulated chyle. Within the cranial cavity there was found some increase of cerebro-spinal fluid at the base of the brain. There was a nodule of growth $\frac{8}{8}$ in. deep by $\frac{5}{8}$ in. wide, and 1 in. in antero-posterior diameter at the vertex close to the longitudinal fissure on the right side, occupying the posterior and inner part of the superior frontal and part of the marginal convolution. A second small growth $\frac{1}{4}$ in. in diameter was visible in the posterior limb of the right internal capsule, and a third nodule $\frac{1}{13}$ in. in diameter on the external capsule at the edge of the lenticular nucleus, just on a level with the former growth. A fourth tumour $\frac{3}{8} \mathrm{in}$. in diameter occurred in the centrum ovale just beneath the cortex on a level with the posterior end of the caudate nucleus. All these lesions were in the right hemisphere. On the left side no new growths were found, but there was a small patch of softening of about the size and shape of a grain of wheat, vertically placed, situated on the anterior limb of the internal capsule. The medulla and pons were normal and there was no apparent disease of the cerebral vessels. No descending degeneration was found in the pons or crura. The spinal cord was unfortunately not preserved. Microscopically the growth was carcinoma consisting of large glandular cells and little intervening stroma.

Remarks.-On the patient's admission the symptoms of crossed paralysis suggested some lesion of the pons, but the slightness of the affection made it difficult to conjecture what the exact nature of this lesion might be. Later, the paralysis appeared to improve and what was left of it was merged in the general weakness resulting from the grave conclition of the patient. Signs of intra-thoracic pressure were now the prominent features of the case : the plenrisy, the character of the fluid withdrawn, and the renous thrombosis in various parts of the body pointed to the probability of malignant disease. 'I'he gastric nlcer found at the necropsy was not diagnosed during life, though the existence of nialionant disease of the stomach had been suspected owing to the emaciation, the epigastric pain and tenderness, and the flatulent dyspepsia. The exact seat of the original cancer could not be determined. The first symptoms were caused by the cerebral growths, which were multiple and eridently secondary. The growth in the ling was the most adranced, and the early occurrence of cough, which had been complained of before admission, might point to this as the original lesion, but the rarity of this seat of primary carcinoma makes the suggestion doubtful. No primary focus could be found in the abdomen to account for the enlarged glands there and it is noteworthy that these iccurred late in the history of the case. Judging from the apparently normal condition of the uterus and appendages no severe operation could have been performed, such as might throw any light on the origin of the malignant discase.

The distribution of the paralysis seems fairly accounted for by the cerebral lesions. The large nodule at the vertex occupied part of the leg area; the growth in the right internal capsule explained the weakness of the arm and indirect pressure exerted by it on the fibres of the posterior limb of the capsule was no doubt the origin of the anæsthesia. The facial paralysis on the other side was apparently due to the minute patch of softening in the left internal capsule, but the origin of this lesion was not easily explicable. It may perhaps have been due to some small venous thrombosis, analogous to those occurring later in other parts, such as seems often to occur in malignant disease. The conjunction of the two distinct forms of lesion on opposite sides of the brain is at least unusual. Another point of considerable interest is presented by the fact that the paralysis on both sides completely or almost completely disappeared, although the organic cause of it on the right side of the brain cannot have lessened in extent and was probably actively progressing. The paralysis must be classed as "functional," due to some disturbance in the activity of the nerve-units, not to their destruction. What, however, the exciting cause of the original fits and the ensuing paralysis may have been must remain unexplained. 'There was no sign of any hæmorrhage into any of the growths such as might have caused a sudden cerebral disturbance. Further, there was no sign of any great increase of intracranial tension, as the convolutions were not flattened, nor was there headache, vomiting, or optic neuritis. In short, the cerebral condition in no way shortened life and had not the thoracic disease progressed so rapidly the patient might have left the hospital relieved of her paralysis, which would have remained entirely unaccounted for.

York-street, Portman-square, W.

\section{TWO CASES OF HALFPENNIES IMPACTED \\ IN THE CESOPHAGUS FOR FIVE AND SIX MONTHS RESPECTIVELY, REVEALED BY $X$ RAYS AND REMOVED.}

BY A. W. MAYO ROBSON, F.R.C.S. ENG.,

SHNIOR SURGEON TO THE GENERAL INFIRMARY AT LEEDS; PROFHSSOR OF SURGERY IN THE YORKSHIRE COLLEGE OF THE VICTORIA UNIVERSITY.

THE following unusual cases came under my observation quite independently of each other within the same week and were treated by me on consecutive operating days in the Leeds General Infirmary.

CASE 1.-A boy, aged four years, was sent to me by Mr. H. Keighley and Mr. J. H. Woods of Batley with the history that six months previously he had swallowed a halfpenny and at the time had almost died from suffocation, which was prevented by his mother's presence of mind in pushing the coin beyond the entrance of the larynx by means of her finger. The coin was supposed to hare passed into the stomach, as although he had some pain in swallowing there was no actual obstruction to the passage of food. Some weeks after he began to have pain in his neck, to have difficulty in swallowing, and to hold his head stiffly to the left side, almost as if he had caries of the cervical spine. He began to lose flesh and to look ill. It was then decided that he should be photographed. by the Roentgen rays. The photograph (by Messrs. Reynolds and Branson of Leeds) was brought with the patient and it shows (vide figure) the coin impacted in the cesophagus at a point opposite the pericardium, where it would also be in close contact with the left pleura and with the aorta. I decided to attempt its removal through the patient's mouth, and that failing I obtained permission to perform œsophagotomy. It was explained to the parents that there might be risk of hæmorrhage or perforation in removing the coin from its bed, but they decider to accept all eventnalities. On Feb. 18th, the patient being under ether, I inserted the coincatcher invented by the late Mr. Sam Smith, and at the 
first introduction I withdrew the halfpenny without any as the patient comes under observation. In cases of doubt difficulty. It was much corroded and covered with greenishblack material. Nothing untoward occurred and the boy left the infirmary quite well the next day.

CASE 2.- The patient was also a boy, aged five years, and the photograph showed the coin in the same position as viously, œsophagotomy was performed without any attempts the new photography can be employed with great advantage, as shown in the two examples I have related. I noticed a report in one of the journals lately that in a similar case, where the coin had been swallowed only a short time pre-

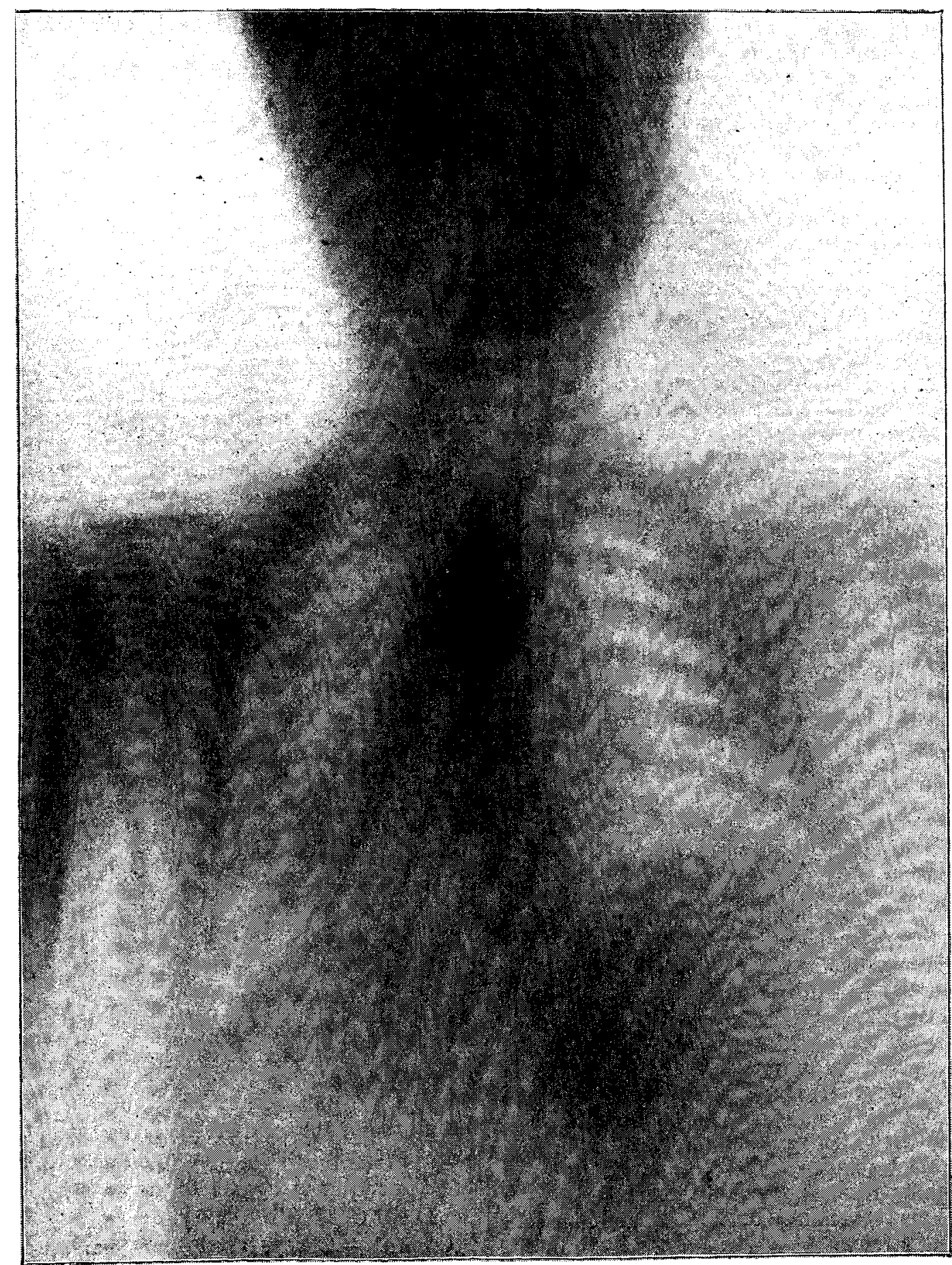

Skiagram showing impaction of halfpenny in the cesophagus opposite the pericardium.

in Case 1. The same treatment was aclopted and with the same result.

The "coin-catcher" is a most ingenious instrument with which I have removed coins recently swallowed on other occasions, and as it is so simple in action and so painless in application it should in any doubtful case be applied as soon being made to remove it through the mouth. My experience would lead me to conclude that such an operation should rarely be necessary and could only be justifiable after the simple means I have related had been thoroughly tried and had failed.

Leeds.
National Society for Euployment of EpilepTICs. - The annual meeting of governors was held on July 11th at the Society's offices, 12, Buckingham-street, Strand, the chair being taken by Mr. E. Montefiore Micholls. In the report for the past year presented by the hon. medical staff it is stated that "a marked improvement has been noted in the majority of cases at the Chalfont Colony," this improvement being especially pronounced in the case of the wemen colonists. The report of the Executive Committee refers to the rapid growth of the Colony as evidenced by the fact that besides one Home for twenty-four colonists recently completed but not yet occupied four others are now in course of erection, the cost having been provided by contributions for this specific purpose. "Yet the increase of accommodation," it is stated, "does not keep pace with the increase in the number of candidates for admission. This constant development and expansion is therefore clearly a necessity, but it is not always realised that every new Home erected at the Colony creates new wants; on the contrary, these extensions lead to the impression that existing wants have been more than adequately supplied." The result is "that the flow of generosity has been checked when the need for it is greatest," and the gravity of the financial position has led H.R.H. the Duke of York, as President, to issue a special appeal on behalf of the society for the sum of $£ 7000$ for certain immediately necessary purposes detailed in the report. 